\title{
BARROCO Y PODER EN LOUIS XIV DE PAULO DE JOLLY ${ }^{1}$
}

\author{
Megumi Andrade Kobayashi \\ Universidad Finis Terrae \\ megumiandrade@gmail.com
}

\begin{abstract}
RESUMEN/ABSTRACT
Este artículo aborda la obra del poeta chileno Paulo de Jolly (1952), figura enigmática y poco conocida de la poesía chilena de los ochenta, quien durante esos años comienza a desarrollar un proyecto poético que consistía en encarnar la voz del rey Louis XIV. A partir de un análisis comparado, se revisa de qué modo mientras sus pares escribían -o intentaban escribir-sobre torturas y desapariciones, Paulo de Jolly le cantaba a los amplios jardines del Palacio de Versalles y enaltecía ideas relacionadas con la voluntad de vivir, la luminosidad de los espacios y lo apacible de la vida de corte. A partir de estos y otros asuntos (como el ofrecimiento de este poemario como modelo de gobierno para Pinochet; la emergencia de una figura de un rey soberano y guerrero, entre otros) se propone una lectura del poemario a partir de los estudios sobre el Barroco.
\end{abstract}

Palabras Clave: Paulo de Jolly, poesía chilena de los ochenta, Barroco.

This article addresses the work of Chilean poet Paulo de Jolly (1952). An enigmatic, little known figure in the Chilean poetry scene, De Jolly begun developing a poetic project in the '80s consisting in embodying the voice of King Louis XIV. Using comparative analysis, this article examines how, while his peers wrote -or tried to write-about torture and disappearances, Paulo de Jolly celebrated the ample gardens of the Palace of Versailles and glorified ideas regarding the will to live, the luminosity in spaces, and the mildness of life in the court. Building on these and other subjects (like the offer of this collection of poems as a model of governance

$1 \quad$ Este artículo surge a partir de la investigación titulada: "Versailles / mi radiante criatura": Louis XIV de Paulo de Jolly", Tesis para optar al grado de Magíster en Literatura de la Universidad de Chile. Alumna: Megumi Andrade Kobayashi. Profesores guía: Luz Ángela Martínez, Felipe Cussen (enero de 2013). Agradezco los comentarios y sugerencias de Nicolás Labarca para la realización de este artículo. 
for Pinochet; the emergence of the figure of an absolute and belligerent king, among others), the article proposes an interpretation of the book based on studies about the Baroque period.

KEYWords: Paulo de Jolly, '80s Chilean Poetry, Baroque.

A principios de los años setenta, Paulo de Jolly, poeta chileno procedente de una familia conservadora, comenzó a desarrollar un proyecto poético extraño para esos álgidos años: asumir y encarnar la voz del mismo Louis XIV escribiendo sus confesiones y memorias. Se trataba de una serie de poemas dedicados a la Francia del siglo XVII y la vida cortesana al interior del Palacio de Versalles, cuya historia, marcada por apariciones y desapariciones, ediciones perdidas y reediciones, se extiende por más de treinta años. Desde un comienzo, la figura de este poeta ha sido enigmática y ha estado revestida por variados rumores y quizás algo de mistificación, un "mito de Jolly" probablemente impulsado por sus propias declaraciones y algunas apariciones públicas vestido de marqués. A esto se suman los rumores de largos períodos de reclusión en un manicomio o casa de reposo a causa de un complejo cuadro de esquizofrenia, lo cual explicaría su desaparición de la vida pública. Esto, desde mediados de los ochenta hasta la publicación de su libro Príncipes, Duques y Mariscales de Francia en el 2003.

En términos de publicación, en realidad no existe un Louis XIV en el sentido de edición final. En los años ochenta, los poemas fueron repartidos en hojas sueltas o pequeños cuadernillos confeccionados por el mismo De Jolly (a Enrique Lihn, Diego Maquieira, entre otros poetas, escritores y amigos de la época). Se trataba de entregas esporádicas que aseguraban una distribución informal que funcionaba fundamentalmente a partir de comentarios, recomendaciones e intercambios de mano en mano. Más adelante, en 1982 -a propósito de haberse adjudicado el Premio Mairena de poesía- aparece en Puerto Rico Louis XIV, publicación en la que se incluye una selección de estos poemas. Sin embargo, este libro tuvo una casi nula distribución en el país. Ya posteriormente, y como primer indicio de su reaparición pública luego de casi quince años de silencio y retraimiento, en el 2003 Paulo de Jolly publica y autoedita Príncipes, Duques y Mariscales de Francia, libro de 26 poemas de los cuales solo uno no había sido publicado en la mítica edición de Puerto Rico (y que tampoco aparecerá después ${ }^{2}$ ). Esta edición también tuvo muy poca 
difusión, probablemente por el hecho de ser autoeditado y porque De Jolly seguía -y sigue siendo- una figura un poco esquiva y enigmática. Finalmente, en el 2006 se publica por ediciones Tajamar una recopilación que reúne una selección compuesta por el corpus completo de poemas dedicados a Louis XIV, que además de los que ya habían aparecido en sus dos libros anteriores (de 1982 y de 2003), consideraba aquellos repartidos en los ochenta y que fueron literalmente rescatados de los baúles de las personas que los habían recibido en estas "entregas esporádicas en bicicleta", como decía Lihn (31). A pesar de las distintas instancias de publicación, los poemas muestran una fuerte continuidad tanto estilística como temática: todos tienen que ver con el "Rey Sol", la vida en palacio con sus fiestas y la vida cortesana. Todos, además, fueron escritos entre 1978 y 1985 aproximadamente.

Tal vez, una de las circunstancias más llamativas de un poeta como Paulo de Jolly es que su obra comienza a gestarse en un contexto en el que -decididamente- cantarle al poder absoluto no era solo anacrónico, sino que por sobre todo incómodo y de mal gusto. Mientras sus pares escribían -o intentaban escribir- sobre torturas y desapariciones, De Jolly le cantaba a lo amplios jardines del Palacio de Versalles. Precisamente, la extrañeza de una obra y un autor como este dentro en un contexto como el Chile de los ochenta (e incluso en el Chile de hoy) es el tema que impulsó adentrarme en este artificial y extemporáneo mundo versallesco ${ }^{3}$.

\footnotetext{
Con respecto a su situación crítica, Paulo de Jolly es una figura que ha pasado prácticamente desapercibida de los registros de la crítica nacional. En los ochenta se publican breves reseñas y algunos de sus poemas en diversos pero escasos diarios y revistas nacionales a propósito de la primera edición de Louis XIV, y desde el 2004 en adelante, fecha en la que vuelve a aparecer públicamente luego de un largo y misterioso silencio, se publican una serie de entrevistas y reseñas en medios como The Clinic y Las Últimas Noticias, donde básicamente se "hace noticia" presentándolo como un escritor excéntrico, explotándolo como un personaje raro de las letras nacionales. Para qué hablar de referencias o estudios sobre su escueta obra, o su inclusión dentro de antologías dedicadas total o parcialmente a su época. Su invisibilidad crítica puede ser pensada por varias razones; las principales, tal vez, su declarada cercanía ideológica con la derecha; su larga temporada de ausencia de la vida pública en la cual se rumorea que habría estado recluido en una "casa de reposo" o encerrado en un manicomio; y la limitada circulación inicial de sus poemas. Sobre este tema, para nada menor en relación con estos extraños poemas cortesanos, trabajé con detenimiento en mi tesis de grado ya citada, en la cual luego de realizar un estudio sobre el contexto político-cultural de los ochenta, y de hacer un detenido análisis de las vicisitudes de la obra y el problema de la invisibilización crítica, propongo una lectura del Louis XIV desde los Estudios sobre el Barroco. Parte de estas reflexiones son expuestas en este artículo.
} 
La lectura de estos poemas desde la comprensión del Barroco como "Barroco de Estado" surge después de mucho tiempo de lectura e investigación. Frente a la declarada conexión del autor con la derecha chilena, en su línea más pinochetista y conservadora (aproximación muy alimentada por un periodismo cultural no solo inocente, sino que a ratos burdo y superficial), desde un comienzo fue necesario tener mucho cuidado con caer en interpretaciones que siguieran alimentando esta idea sin una mayor problematización.

El punto de partida de esta lectura tiene que ver con la siguiente propuesta: es posible rastrear el lado más oscuro del Louis XIV a partir de ciertos ruidos que se producen en la lectura de los poemas, pequeños quiebres que de alguna manera desestabilizaban la interpretación de ésta como una poesía del deleite, de la candidez y de la voluntad de vivir, características que, como iremos viendo, son también parte importante de la obra de Paulo de Jolly.

Estos ruidos que señalo fueron haciéndose cada vez más evidentes luego de revisar varias veces el poemario y empezar a ver que entre tanto jardín, palacio, festejo y madame, se cuelan también imágenes un poco bizarras, grotescas incluso, que de tanta siutiquería e impostación "cortesana" caen en su extremo opuesto. Los poemas esconden también cierta crueldad, cierta dureza que no se armoniza con el retrato de tardes apacibles en palacio o paseos a través de los campos. Este mundo versallesco no es solo mesura, dignidad o pureza del alma; de alguna manera, el libro tiene su cuota perversa. La transparencia, de tanta claridad, de tanto brillo, oculta con sus trajes de oro, sus vestidos de seda, una parte importante de lo que la acompaña: la imagen autoritaria, el poder de mando, la voluntad del soberano.

La dificultad de situar o de caracterizar el tremendamente ambiguo hablante de los poemas fue un obstáculo a la hora de proponer esta lectura oscura del poemario. Como veremos, esta se constituye a partir de la recopilación y análisis de versos sueltos o partes de poemas, con los cuales considero que es posible armar el modelo de gobernante que de ellos se desprende. Aquí no interesa tanto el poeta-rey que pasea por sus jardines, que confiesa sus pasiones amorosas o que describe el enorme encanto de su Palacio. La atención estará puesta, en cambio, en aquellos poemas-memorias en los cuales el rey muestra su calidad de soberano en toda su amplitud: como hombre de gobierno y como hombre de guerra. A pesar de esta complicación propia de la indeterminación y tremenda movilidad del hablante, dentro de los ochenta y cuatro poemas que componen el Louis XIV existe uno muy significativo en el cual esta característica constante se interrumpe. Se trata de un poema 
clave donde esta ambigüedad deja de ser tal, y el hablante se muestra directa e inequívocamente autoritario, severo e incluso cruel y fascista.

Insisto en este poema, probablemente uno de sus más conocidos: "Louis XIV y los pobres", porque cuando en octubre de 2012 entrevisté a Antonio Cussen -quien trabajó directamente con Paulo de Jolly para la publicación de Tajamar- éste comentó un dato interesante. Este poema, al parecer, causó controversia entre quienes participaron del trabajo casi arqueológico de rescate, selección y edición del Louis XIV: Diego Maquieira, Arturo Fontaine, Raúl Zurita, Alejandro Kandora y el mismo Paulo de Jolly (quien habría tenido muy poca participación, a pesar de su condición de autor). Todos, salvo Antonio Cussen, autor de Mecenas (2001) ${ }^{4}$, opinaban que éste sí debía ser incluido. Cussen, sin desconocer su calidad, consideraba en cambio que dentro de esta pequeña narrativa que de alguna manera va construyéndose a lo largo del libro, y sobre todo respecto de la muy bien lograda ambigüedad enunciativa del hablante -que transita hábilmente, incluso dentro de un mismo poema, entre el deleite, la inocencia, la ironía y la crueldad- la decisión de incluir "Louis XIV y los pobres" perjudicaba esta perfección, sostenida precisamente en la incapacidad de fijar establemente desde dónde (con qué tono, con qué intención) es que se enuncian estos poemas.

Incluso con una rápida lectura del libro, al llegar a éste la disonancia respecto del resto es bastante evidente:

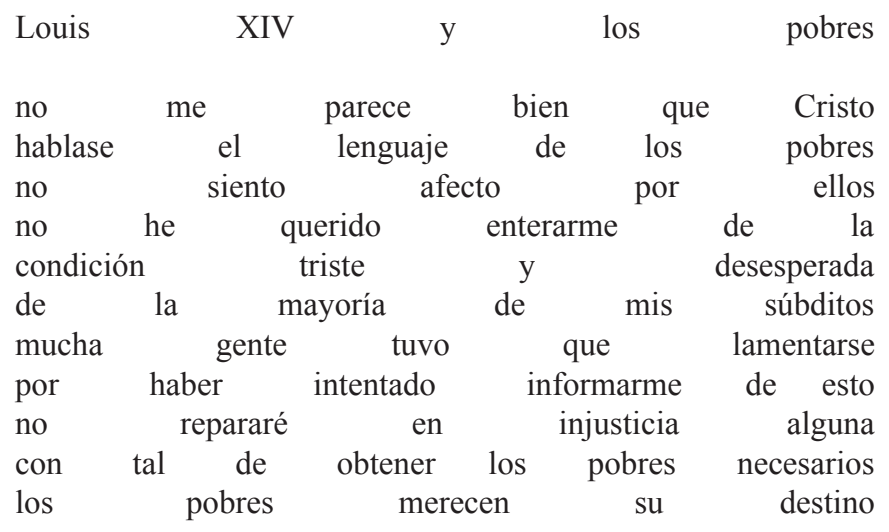

(De Jolly 74)

$4 \quad$ Poemario que al igual que el Louis XIV hace uso de la forma del monólogo dramático. 
Me interesa volver sobre este poema más adelante. Lo propongo desde un principio, y señalo los argumentos detrás de la discrepancia respecto de su inclusión, para afirmar más establemente esta lectura que propongo de la obra desde el "Barroco de Estado". De alguna manera, sin importar que haya querido o no ser incluido, por el hecho de formar parte del poemario en su versión definitiva me sostengo de él, como si de un ancla se tratara, para conducir este análisis que pretende focalizarse en los rincones más sombríos de la obra.

En gran medida, y en esto quisiera ser muy enfática, el Louis XIV no es lo uno ni lo otro de modo excluyente, sino que su atractivo está precisamente en el delicado cruce que se produce entre lo más brillante y luminoso del versallesco mundo del Rey Sol, y su propia gota de demonio que lleva dentro.

Ante la pregunta de en qué sentido su libro es un libro político, Paulo de Jolly responde: "en en sentido que canta al poder absoluto" (De Jolly, Una Belleza Nueva).

Desde su primera visita a Versalles, en 1971, el poeta declara quedar absolutamente fascinado por la suntuosidad de sus jardines, la amplitud de sus salones, el decorado y la magnificencia de esta gran obra arquitectónica, iniciándose en ese momento una obsesión que traspasará lo meramente libresco e intelectual. Como hemos visto, De Jolly pretende convertirse en un anacrónico poeta de la Corte y en el mismo poeta-rey, tanto dentro como fuera de sus poemas.

En esta, su mítica primera visita, cuenta que escribe en una servilleta sentado en un banco de los jardines del Palacio el poema inaugural de la enorme serie dedicada al Rey Sol:

Flota en este chambergo adornado de perlas el mayor plumaje que pueda recordar las alas del divino tocado

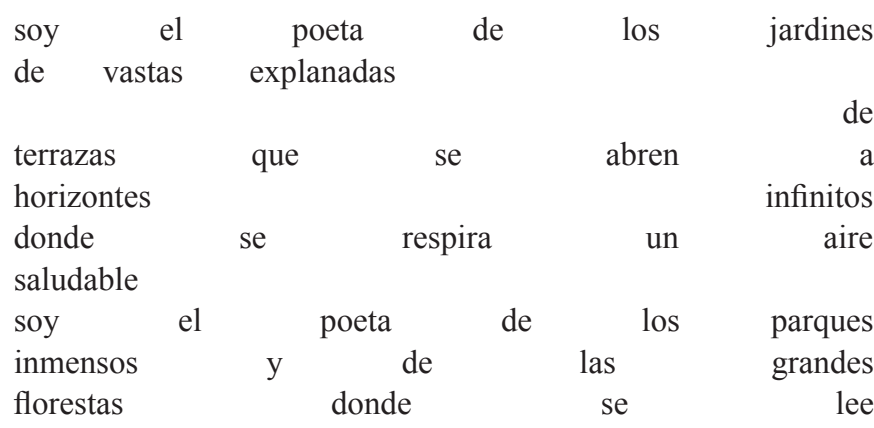




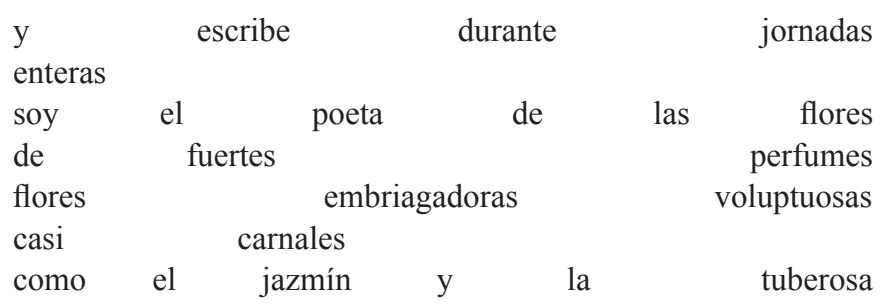

(De Jolly 16)

Sin embargo, revisando las fechas, este poema -que por algún motivo no aparece publicado en la edición de Puerto Rico de 1982-muy probablemente no lo escribió sino hasta fines de la década del setenta. Es más, en varias entrevistas asegura que recién comienza a producir su Louis XIV en 1978. ¿Por qué insisto en esto? No por querer probar la veracidad o no de sus declaraciones; es más, es parte importante de su automitificación el relato de haber escrito en su primera visita a Versalles un poema nada menos que en una servilleta y sentado en una banca, como poseído por una gran inspiración. Lo que me interesa con esta precisión es desmarcar la escritura de este poema de la fecha señalada, 1971, para situarlo más adelante, en pleno período de dictadura militar.

Tal vez lo más curioso - por llamarlo de alguna manera- de esta obsesión palaciega es que el proyecto poético mismo se inicia y comienza a cobrar cuerpo en los años más duros y álgidos de la represión dictatorial chilena. Como señala Felipe Cussen, "en una época en que la palabra poética se veía obligada brutalmente a una condición de lucha y denuncia” (párr. 2), y donde mucho de lo que se estaba produciendo en términos artísticos y literarios se vuelca a una estrategia de enciframiento y complejización discursiva que pretende ser capaz de burlar la vigilancia del aparato represor ${ }^{5}$. Bajo este contexto, si volvemos al poema recién citado, estas sentencias autobautismales: "soy

Trabajo detenidamente este tema al interior de mi tesis. Por un tema de espacio, dejo señalados los autores que se han dedicado al estudio de la producción artística y cultural bajo el contexto dictatorial chileno. Véase particularmente: Soledad Bianchi. Poesía Chilena (miradas, enfoques, apuntes); Rodrigo Cánovas. Lihn, Zurita, Ictus, Radrigán: Literatura chilena y experiencia autoritaria; Idelber Avelar. Alegorías de la derrota: la ficción postdictatorial y el trabajo del duelo; Eugenia Brito. Campos Minados (Literatura post-golpe en Chile); José Joaquín Brunner. La cultura autoritaria en Chile; Nelly Richard. Políticas y estéticas de la memoria. 
el poeta de los jardines / de vastas explanadas / de / terrazas que se abren a / horizontes infinitos / donde se respira un aire / saludable" (De Jolly 16), resuenan a algo más que a un delirio monárquico antojadizo. El jardín como el espacio de la apertura, donde es posible respirar, no cualquier aire, sino un "aire saludable", se contrapone radicalmente a la brutalidad de la vigilancia y represión por la que estaba pasando el país en ese entonces. Y luego, más adelante: "soy el poeta de los parques / inmensos y de las grandes / florestas donde se lee / y escribe durante jornadas / enteras" (De Jolly 16). No hace falta insistir en lo antagónico de esta imagen respecto de las condiciones artísticas y culturales de la época.

Tanto la condición como las implicancias de esta extraña poesía del deleite, de la sofisticación y del artificio se complejizan aún más cuando atendemos, nuevamente, a declaraciones del propio autor. Precisamente, ante la pregunta de si la contingencia de los años 80 lo estimuló para escribir poemas, De Jolly responde: "Mi idea con Louis XIV era darle un modelo a Pinochet para que hubiese impulsado un renacimiento de las artes en el país, con palacios, ópera, ballet y literatura. Pero mi libro pasó desapercibido" (De Jolly, "Mítico poeta..."). En este punto es importante recordar que Paulo de Jolly actúa en la vida real como si fuese -indistintamente- un sujeto cortesano, el poeta oficial de la corte y el mismo Rey Sol ${ }^{6}$; en sus textos, el hablante corresponde al poeta-rey; y toda su obra, que persigue representar hasta los detalles más íntimos de la vida del monarca y la vida de palacio, se pretende erigir como modelo ideal de gobernante para Pinochet, para que bajo su mandato éste logre promover una completa renovación artística y cultural en el país, del mismo modo en que Louis XIV significó un período de gran esplendor para la historia de Francia.

Dentro de este enredo de modelos y representaciones es importante detenerse en una cuestión relativa al verdadero Louis XIV. La imagen del monarca francés como reformador y revitalizador de la nación ha sido creada por la historiografía no solo a partir del gran impulso artístico y cultural que éste implantó bajo su reinado, sino que además por el hecho de haber asumido el gobierno en un período de grandes convulsiones, en medio de la anarquía y con las finanzas afectadas por los enormes despilfarros de

${ }^{6} \quad$ Se tiene noticia de esto a partir de una serie de declaraciones hechas por el mismo autor en notas, entrevistas y lecturas poéticas, además de una serie de rumores que circulan en el mundo literario nacional (alimentados, entre otros, por el mismo Enrique Lihn). 
Fouquet (el encargado de hacienda del reino). Es decir, existe una dimensión política y económica importante detrás de la grandeza con la que ha sido caracterizado el Rey Sol. Superando estos obstáculos que requerían no solo de un hombre sensible y afín a las artes, sino que fundamentalmente de un soberano firme y poderoso, es que Louis XIV se convierte en la gran figura del monarca absolutista por excelencia, siendo venerado de ese modo incluso hasta la actualidad.

No por nada el mismo Voltaire, en 1751, declara que con la época de Louis XIV, después de la era de Filipo y Alejandro en Grecia, César y Augusto en Roma y los Médicis en Italia, se erige en Francia una cuarta edad feliz, en la cual se habría efectuado "en nuestras artes, en nuestros espíritus, en nuestras costumbres, así como en nuestro gobierno, una revolución general que será testimonio eterno de la verdadera gloria de nuestra patria" (Filebo, "Paulo de Jolly..." 26).

Recojo estas referencias porque hay algo que me parece relevante en los ecos que se pueden observar entre algunos aspectos específicos del contexto inmediato de producción de Paulo de Jolly y lo que desde una mirada bastante nacionalista se ha constituido, dentro de la historia de Francia, e incluso dentro de la historia europea en general, como el relato oficial de una época particular y especialmente esplendorosa que se constituyó como tal gracias a una figura monárquica divinizada que le hace frente -victoriosamente- a una coyuntura inestable y conflictiva.

El paralelo que me resulta interesante es el que se puede llegar a establecer entre este relato oficial de la historia de Francia (con su respectivo soberano) con otro relato histórico, mucho más criollo y contemporáneo. Me refiero a cómo gran parte de la derecha chilena ha leído el levantamiento de una figura como Augusto Pinochet frente al gobierno socialista de Salvador Allende. Es tal vez necesario recordar que para muchos de ellos Pinochet no fue sino el libertador de la patria del cáncer marxista y su desastre económico y social. Es decir, una figura también con tintes mesiánicos, que bajo una estampa patriarcal, autoritaria y militarizada logra imponerse y controlar el desorden económico, moral, social y cultural que según ese sector de la sociedad chilena estaba afectando terriblemente a la nación en ese entonces.

¿Habrá visto Paulo de Jolly alguna conexión entre su Louis XIV y Pinochet, o viceversa? Ambos patriarcales, autoritarios y hombres de guerra. Ambos, además, asumen el poder -por los motivos que sea- en un momento de inestabilidad generalizada y crisis económica, con la pretensión no solo de restablecer el orden sino que también y fundamentalmente refundar la historia 
de sus naciones, marcar un antes y un después a partir de la instauración de un nuevo reinado que estuviera bajo su propia dirección.

Si tuviéramos que hablar de una constante del Barroco de todos los tiempos es su estrecho vínculo con el poder. Este vínculo, tal y como lo estoy proponiendo, es bastante evidente para el caso de la obra de Paulo de Jolly. La comprensión del Barroco como "Barroco de Estado" tiene que ver con un discurso que forma parte de un proyecto expansionista que pretendía unificar en torno a un rey, a un dios y a un solo idioma todo el dominio imperial (Beverley 84). Es en el contexto de las cortes virreinales donde este discurso barroco se instala para consagrar el domino de una nobleza cortesana, el orden eclesiástico y la burocracia estatal, que dentro de esta sociedad fuertemente jerarquizada en castas, se posicionaban en un nivel superior ${ }^{7}$ (Vidal, Moraña, Picón Salas, Leonard, Acosta). El asunto es que el Barroco así entendido se establece como modelo comunicativo utilizado tanto por españoles (que resultaban ser, hacia el siglo XVII, una minoría) y la cada vez más numerosa oligarquía criolla. A través de este modelo, como bien escriben Vidal y Moraña es que el "Estado imperial exhibía su poder bajo formas sociales altamente ritualizadas" (Moraña 30). Se trataba en definitiva del lenguaje oficial, el cual era presentado y legitimado permanente y visiblemente a partir de la misma ciudad virreinal y su fisonomía, y muy especialmente a partir de certámenes, ceremonias públicas y la literatura de cortes. Con respecto a esto último es que John Beverley articula su concepto de "Barroco de Estado", a partir del caso específico del gongorismo implantado en América como discurso poético del poder metropolitano que transmite, como bien dice, "no solo un signo de ascendencia social sino también una técnica de poder social, un instrumento de legitimación y dominación" (Beverley 84). En este sentido es que la pretensión de Paulo de Jolly de ofrecer este modelo de monarca ideal, al cual se lo venera y admira, para ejercer desde la poesía una influencia directa en el devenir histórico del país, adquiere una condición que se ajusta muy bien a esta idea del "Barroco de Estado". Así, al igual que con el gongorismo implantado en América como discurso poético oficial del poder metropolitano, la literatura

\footnotetext{
Véase: Leonardo Acosta. "El barroco americano y la ideología colonialista"; Emilio Carilla. Manierismo y Barroco en las Literaturas Hispánicas; Jaime Concha. "La literatura colonial hispano-americana: problemas e hipótesis"; Irving, Leonard. La época Barroca en el México Colonial; Mabel Moraña. Viaje al silencio. Exploraciones del discurso barroco; Mariano Picón Salas. De la Conquista a la Independencia. Tres siglos de Historia cultural Hispanoamericana.
} 
se pone al servicio de intenciones apologéticas del Estado imperial, la obra de Paulo de Jolly se puede interpretar como un discurso que a la vez que le canta al poder absoluto (y por lo tanto, lo recupera y legitima), se pone también al servicio de una determinada estructura de dominación. En este caso, la estructura de la dictadura militar.

Según el crítico chileno Luis Sánchez Latorre, en un texto de 1967 en el que Alone escribe sobre el Rey Sol, este habría sentenciado: "La divinización del poderoso se cumplió en Luis XIV como sólo se ha observado en la época moderna en los casos de Hitler y Stalin" (Filebo, "Paulo de Jolly..."). De un modo cuidadoso y disimulado, puesto que se trata de una nota publicada en el diario Las Últimas Noticias en junio de 1985, Filebo se cuelga de esta reflexión que acabo de citar y apunta: "No adivinaba, entonces, Alone, por cierto, que luego vendrían otros. Y otros", refiriéndose con esto nada menos que a Pinochet, que puesto a un lado de Hitler y Stalin suena no solo a autoritarismo, sino que también a cierto fascismo de Estado. En esta brevísima pero aguda reseña, Filebo -sabiendo o no las intenciones del poeta-advierte este vínculo entre poder y adoración, entre poder y literatura, a partir del cual podemos considerer que la apología de Paulo de Jolly no tiene para nada un carácter inocente.

Probablemente, dadas las circunstancias en las que esta reseña es publicada, Filebo deja lugar a las conjeturas respecto de una crítica a la figura de Pinochet pero no sin antes advertir una idea que creo da cuenta de una lectura muy acertada de estos poemas: "El malentendido estriba en pensar que Paulo de Jolly se refiere a cosas de un siglo sepulto. No. Error muy grueso. Paulo de Jolly desliza su mirada profunda sobre un mundo que le es completamente actual. Esta actualidad salta a la vista" (Filebo, "Paulo de Jolly...").

Volviendo a las coincidencias y posibles resonancias entre el siglo XVII francés y el Chile de la dictadura, es también evidente que existe una importante diferencia entre un lado y el otro, entre el modelo y su copia, una distancia que el propio Lihn logra intuir en una reseña del Louis XIV escrita en 1985. Al contrario de la erudición y sensibilidad propia del verdadero Louis XIV, o al menos de los personajes que lo rodeaban, la dictadura chilena "prosaica [en el sentido de insensible o incluso vulgar] y poco culta" (Lihn 31) nunca estuvo a la altura de un poeta tan "sofisticado y desafiante" como Paulo de Jolly. "Ningún Chapelain ha empleado sus servicios; al Colbert chileno, si existiera, le sería indiferente un libro como Luis XIV" (Lihn 31). Es decir, Pinochet y su corte eran, a juicio de Lihn, demasiado toscos, demasiado 
brutos como para llegar a apreciar en algún sentido toda la conmovedora belleza de estos poemas.

Como vimos, el mismo De Jolly da cuenta de esta distancia cuando dice que a pesar de su idea de presentar su libro como modelo de gobierno para Pinochet, éste "pasó desapercibido" (De Jolly, "Mítico poeta..."). Y en otra entrevista, luego de declarar abiertamente su pasado pinochetista, dice haberse arrepentido al poco tiempo de su militancia al percatarse de los abusos del régimen. "Yo a él (a Pinochet) lo encontraba muy soberbio" (De Jolly, "En Chile se puede...").

Más allá de creer o no en su arrepentimiento, el hecho es que en una época en la que parte importante de los intelectuales eran opositores al régimen, Paulo de Jolly era declaradamente pinochetista. Como hemos visto, la misma disonancia ocurría con su obra. Mientras él poetizaba sobre "la alegría de vivir" (99); "la fuerza total de la belleza" (15); "las alegrías sanas del amor físico" (54); "los jardines de vastas explanadas" (16) y "los placeres de la Isla Encantada" (52), la mayoría de los escritores y poetas escribían sobre cuestiones políticas en el sentido de denuncia y/o exposición de los maltratos $\mathrm{y}$ abusos cometidos. Todo esto, articulado en general desde un lenguaje complejo, muchas veces encriptado y lleno de referencias indirectas, que poco o nada tienen que ver con la simpleza y claridad casi prosaica de los versos del Louis XIV.

$\mathrm{Al}$ detener la mirada en los modos de configuración y caracterización del espacio creo que se puede llegar a reconocer muy bien estos contrastes a los que me refiero. Vuelvo sobre el poema citado más arriba, "Flota en este chambergo adornado de perlas...", porque este condensa muy bien cómo es este poeta-rey (es decir, cómo se configura este sujeto poético), y por otro lado, la visión bucólica e idealizada de la vida cortesana que se presenta: " soy el poeta de los jardines / de vastas explanadas / de / terrazas que se abren a / horizontes infinitos / donde se respira un aire saludable / soy el poeta de los parques / inmensos y de las grandes / florestas donde se lee / y escribe durante jornadas / enteras ${ }^{8}$ (De Jolly 16). Decía más arriba que estas sentencias autobautismales establecen muy claramente que el espacio al cual pertenece y del cual habla este poeta-rey se distingue por su cualidad apacible y liberada. A pesar de ser un jardín, y como tal un lugar artificialmente creado, este parece no tener límites. Ahí se siente plenamente complacido 
y envuelto en la quietud necesaria y suficiente como para dedicarse a nada más que a la lectura y a la escritura. Ya veremos más adelante que esta idea de las "jornadas enteras" entra en conflicto con este rey que también tiene la responsabilidad de gobernar. Por lo pronto, es evidente lo antagónico de esta imagen, no solo con respecto a las condiciones artísticas y culturales de la época, sino que también respecto de los modos en los que se configuran los espacios en las obras de otros poetas que por esos años estaban también escribiendo9.

Cito unos versos de El Primer Libro de Soledad Fariña, publicado dos años después del Louis XIV (en 1985) pero que, al igual que éste, comenzó a ser escrito desde fines de los setenta:

- Por qué tan tristes por qué así estos colores, dicen, preguntan los choroyes de alas verdes que pasan en bandadas

- Por qué esa oscuridad, gritan

- Hay un negro que sombrea que nos cubre

Se alejan pero no alcanzan a ver el rojo que descubro debajo de mi axila

- No hay claridad, no hay claridad, graznan

- Ha caído la nube gris sobre mi vuelo: eran granizos era hielo el que quebró mis alas

(Fariña La Vocal 19)

Este fragmento corresponde al primer poema con el cual se inicia este libro de Soledad Fariña, que tal y como ha sido señalado por la crítica ${ }^{10}$, tiene una clara relación intertextual con el mito maya-quiché contenido en el Popol

$9 \quad$ A lo largo de la investigación no fue posible comprobar si "De Jolly" es efectivamente el nombre real del autor o si corresponde a su seudónimo. En caso de ser inventado, resulta interesante considerar su cercanía con "jolli”, que en francés significa "bonito/a". De más está decir que se trata de un adjetivo que contrasta fuertemente con su contexto inmediato.

10 Véase: María Teresa Adriasola. "Lo sagrado del Primer Libro: El libro de la creación"; Raquel Olea. "Soledad Fariña: Hacia una poética del deseo"; Javier Bello. "Hacia una poética de Soledad Fariña. Prototexto y escritura cifrada en La vocal de la tierra". 
Vuh (o "libro de la comunidad"). Lo interesante de esta reescritura es que a esta apropiación discursiva del mito genésico precolombino simultáneamente se le cuelan imágenes que, de un modo condensado y encriptado, intentan testimoniar el trauma de la experiencia de la dictadura. Por otra parte, en una lectura más extensa del poemario, que no cabe realizar detenidamente aquí pero que señalo brevemente, la imagen de aquellos granizos que quiebran las alas de el o la sujeto, imagen que intertextualmente se vincula con las escenas diluviales presentes tanto en el Génesis cristiano como en el Popol Vuh, se podría llegar a asociar con el bombardeo de La Moneda ocurrido durante el Golpe de Estado de 1973.

Otra disonancia importante entre un poema como este y el de Paulo de Jolly tiene que ver con cómo se presenta y escenifica el sujeto poético. En el poeta versallesco queda muy clara la identidad del sujeto así como también el lugar que ocupa en el espacio: "soy el poeta de los jardines / de vastas explanadas"; "soy el poeta de los parques / inmensos"; "soy el poeta de las flores / de fuertes perfumes" (De Jolly 16). Si volvemos sobre los versos de Fariña, ahí, en cambio, éste se manifiesta indirectamente o simplemente evita manifestarse - desde el diálogo de los choroyes-, y cuando aparece físicamente lo hace fragmentariamente, a partir de un sector indeterminado del cuerpo: "el rojo que descubro / debajo de mi axila". No la axila misma, sino que más abajo de ella; ¿pero dónde? A diferencia del sujeto centrado y de alguna manera propietario del espacio que se mostraba en el poema anterior, aquí este casi no aparece.

Esta imagen de la axila, por lo demás, logra condensar varios sentidos que están latentes a lo largo de todo el Primer Libro: la rojez de la sangre propia de la rasuración; la rasuración como el corte o la amputación de un crecimiento natural; la rasuración como imposición de un modelo de belleza (y ahí la lectura feminista que se ha hecho a la obra); la violencia sobre el cuerpo femenino; la violencia sobre los cuerpos; un cuerpo que intenta conformarse pero que no puede o no quiere hacerlo; los cuerpos heridos; los cuerpos torturados; etc.

Además de esta, existen numerosas obras producidas durante esos años en las cuales es reiterativa la existencia de espacios lúgubres, inestables, cerrados y/o amenazantes. Por nombrar solo algunos, están los libros $L a$ ciudad (1979) y Virus (1987) de Gonzalo Millán; Huiros (1979) de Jorge Montealegre; Aguas servidas (1981) de Carlos Cociña; El agua que me cerca (1983) de Alejandra Basualto; Via Pública (1984) de Eugenia Brito; y Zonas de peligro (1985) de Tomás Harris. A diferencia de éstos, lo que se transmite 
en los poemas del Louis XIV no tiene nada que ver con el padecimiento, el descontento o la necesidad de denuncia. Como hemos podido ver, esta es una poesía que celebra la vida y la creación como si ésta se pudiera desenvolver tranquilamente.

Por otra parte, los eventos que ocupan la atención del poeta-rey son en su mayoría fiestas en la corte, paseos y encuentros amorosos. Y los espacios predilectos, aparte de "los jardines de vastas explanadas", son estrictamente aquellos vinculados a su Palacio. Todos estos, como es de esperarse, siempre descritos como lugares tranquilos, suntuosos, fascinantes. En "Francia 1667", por ejemplo, se escribe:

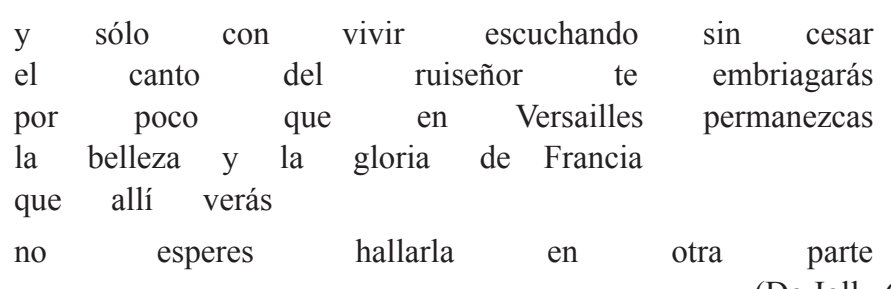

(De Jolly 60-61)

En gran medida, todas estas imágenes del espacio armonizan muy bien con el temple de los sujetos ahí representados. Es decir, se produce una coincidencia importante entre éstos; la apacibilidad del mundo es correspondiente con las posibilidades contemplativas e incluso gozosas del rey y de quienes habitan o transitan por dichos espacios.

Volviendo al poema anterior, "El amor pulsional...", si nos fijamos en los dos primeros versos es posible percatarse de que estos son radicalmente contrastantes con la tristeza, el encierro y la oscuridad que, como veíamos, caracterizan parte importante de la poesía escrita durante esos mismos años. Basta con recordar el poema de Fariña, o con confrontar el sentido de apertura propuesto en estos poemas de Paulo de Jolly (asociado a la libertad, a la distención, a la vitalidad) con la modulación que esta adquiere, por ejemplo, en la primera parte del poema inaugural de La Ciudad (1979) de Gonzalo Millán:

1.

Amanece.

Se abre el poema.

Las aves abren el pico.

Cantan los gallos. 
Se abren las flores.

Se abren los ojos.

Los oídos se abren.

La ciudad despierta.

La ciudad se levanta.

Se abren llaves.

El agua corre.

Se abren navajas tijeras.

Corren pestillos cortinas.

Se abren puertas cartas.

Se abren diarios.

La herida se abre. (9)

Como vemos, este amanecer que, al igual que el poema citado de Fariña corresponde también al primer poema del libro, a pesar de tener el sentido de nacimiento, de comienzo y apertura, rápidamente se conecta con una percepción insegura y amenazante de la ciudad. La apertura del poema es también la apertura de la herida, y esta herida, puesta en el contexto en el que el libro fue escrito, permite una lectura que no puede ser más clara.

Curiosamente, en el poema de Soledad Fariña también se da esta misma relación entre cuerpo y escritura, en un espacio, además, que también dista de ser ligero, luminoso o agradable (a pesar de la condición de nacimiento que, al igual que el amanecer del día del poema de Millán, tiene todo relato genésico): "arañar un poco lamer los dedos para formar / esa pasta ligosa / untar los dedos los brazos ya estás abierto / páginas blancas abiertas no hay recorrido previo / tratar de hendir los dedos" (Fariña La vocal 19).

La luminosidad es otra característica de estos espacios versallescos que, puestos, por ejemplo, a un lado de estos versos del libro Filiaciones (1986) de Eugenia Brito: "La oscuridad cerró todas las puertas. / Me despertaron híbrida: / no fui más que al borrarse los contornos" (155), no pueden ser más disonantes. En el caso del siguiente poema del Louis XIV, esta luminosidad, si bien artificial, hace resplandecer el Palacio con tal vigor que, tal y como señala su título, hace que Versalles parezca un incendio:

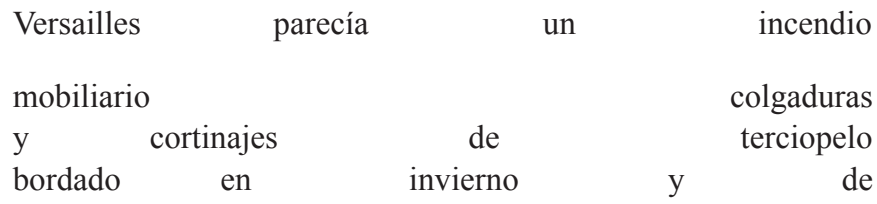




\begin{tabular}{|c|c|c|c|}
\hline vaporosa & seda & en & verano \\
\hline enteramos & $\operatorname{los}$ & siglos & jugando \\
\hline al & & & garito \\
\hline en & ciudad & de & los \\
\hline candelabros & & de & plata \\
\hline por cien & mil & & bujías \\
\hline en & & & arañas \\
\hline
\end{tabular}

(De Jolly 93)

El mismo material con el que están decorados estos salones ayuda a potenciar su carácter resplendeciente. "Terciopelo / bordado en invierno" y "vaporosa seda en verano". Esta ciudad "de los candelabros de plata" (93), a diferencia de la de Millán, irradia luminosidad hasta el exceso. La de Millán, en cambio: "El día declina. / Se enciende el alumbrado. / La ciudad se ilumina. / Las mariposas rondan la luz. / Con la edad las fuerzas declina. / Años de pocas luces. / Estos mis últimos años. / Vivimos en la oscuridad" (19).

Me interesa dar cuenta de qué manera y bajo qué criterios se produce esta distancia entre el Louis XIV y parte importante de la poesía escrita durante esos mismos años. De alguna manera, estas contraposiciones entre el poemario y estas otras producciones (apertura/encierro; tranquilidad/ amenaza; certeza/incertidumbre; luminosidad/oscuridad), caracterizan muy bien parte importante del poemario y su posición dentro de la escena poética chilena de la época. A estas habría que añadir, además, la tensión entre un cuerpo amenazado o herido, y el cuerpo del deleite en De Jolly, que no deja de ser un contraste inquietante ${ }^{11}$.

A pesar de todo esto, y aquí el vínculo con el contexto que sospechábamos ausente se vuelve de inmediato - si bien delicado- tremendamente intenso, estas contraposiciones tienen también su reverso, en la medida en que en el libro de Paulo de Jolly, al tiempo que se constituye este mundo, se entrega también un modelo de monarca tanto en su dimensión de hombre de gobierno como de hombre de guerra. Un modelo que, como hemos visto, en su momento fue pensado como ejemplo para Pinochet.

11 Recordemos en esto lo que ocurre, por ejemplo, en relación con un poemario como el de Fariña. 
De tal manera, esta apertura, tranquilidad, certeza y luminosidad con la que se representan los espacios versallescos, si bien es tal, al mismo tiempo que chocan con sus pares contemporáneos contrastan también internamente al momento en el que atendemos a la dimensión más oscura de este poetarey. Un personaje, finalmente, que no solo se ocupa de sus fiestas y de sus paseos por los jardines, sino que también se manifiesta y hace valer en su condición de soberano.

Es posible apreciar dentro del libro el desarrollo de una pequeña narrativa que tiene que ver, fundamentalmente, con el proceso formativo espiritual y existencial del poeta-rey ${ }^{12}$.

Así como "Alegoría..." puede ser leído como una la última declaración pública o la última memoria del rey escrita a su hijo, el primer poema titulado "El rey sol" es claramente una especie de advocación en la cual lo que se muestra es un soberano ni tan grandioso ni tan seguro de sí mismo como el que encontramos hacia el final del poemario.

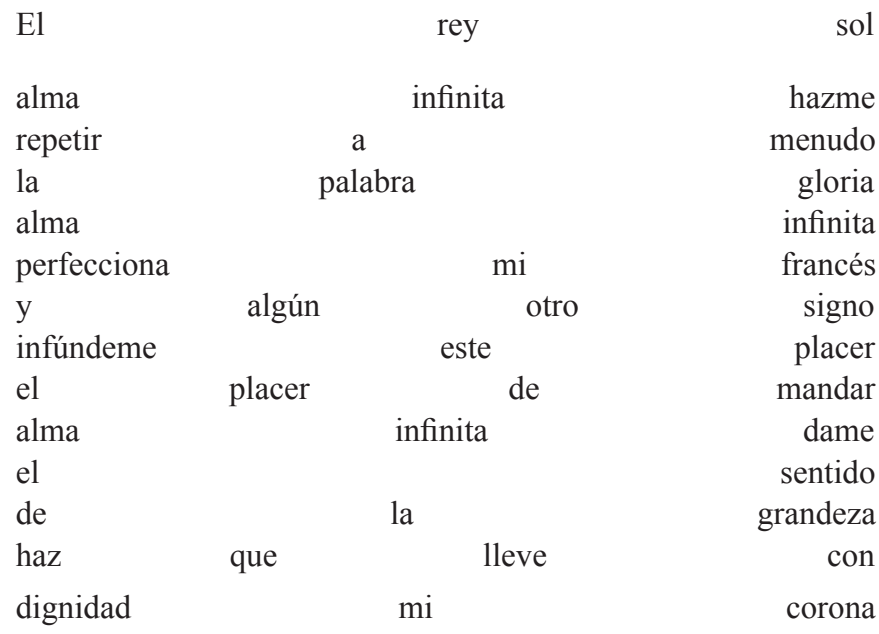

(De Jolly 11)

12 Desarrollo esta idea más detenidamente al interior de mi tesis. Ahí vinculo, además, la disposición visual de los poemas con los jardines del Palacio de Versailles. 
Hay varios asuntos de este poema que resultan importantes. La invocación -a la manera de los poemas clásicos-salta inmediatamente a la vista, solo que en este caso no se dirige a las musas, sino que a esta "alma infinita" repetida tres veces, a manera de estribillo. También resulta curioso que este Rey Sol, al parecer, no maneja en su totalidad el idioma francés: "alma infinita / perfecciona mi francés". Aquí, tal vez, se cuela una pequeña referencia al criollo Paulo de Jolly.

Ahora bien, con respecto a cómo se construye poéticamente esta figura modélica y soberana del rey, este primer poema es muy significativo en tanto da cuenta de la aspiración de este monarca recién investido y que, a pesar del título, todavía no es el Rey Sol. Deseo de gloria, poder tener el placer de mandar, adquirir el sentido de la grandeza y, sobre todo, lograr llevar con dignidad su corona. Todos estos, atributos por alcanzar ${ }^{13}$.

Su personalidad intransigente y autoritaria comienza a aparecer más adelante. Por ejemplo, en el décimo poema del libro, "Louis XIV se sentía a gusto", se escribe: "no me gusta que me fuercen la / mano" (De Jolly 20). Esta característica se vuelve evidente sobre todo cuando el sujeto poético se muestra dispuesto a imponer su voluntad por sobre cualquier obstáculo que se le presente:

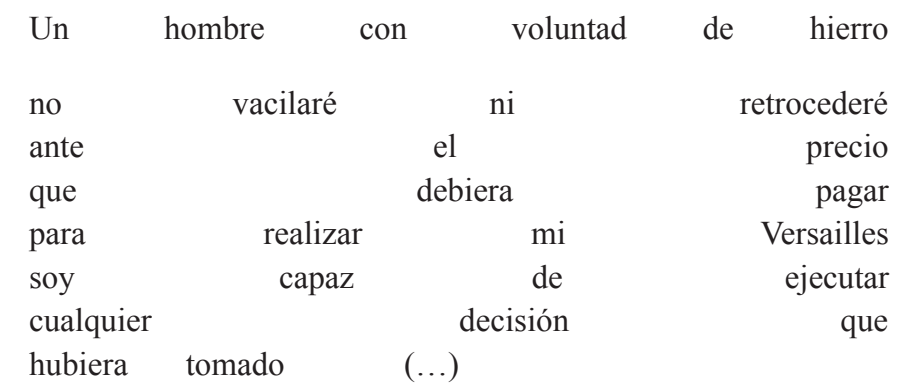

(De Jolly 73)

13 Por otra parte, llama la atención de qué manera en algunos de estos poemas el autoritarismo y el poder de mando están vinculados con el deseo: "infúndeme este placer / el placer de mandar". Esto no es para nada menor si se atiende al hecho que dos constantes del poemario son tanto las aventuras amorosas del rey como su condición de jefe de Estado. Este es un tema que queda pendiente para futuras investigaciones. 
En este mismo poema aparece un verso que condensa esta dualidad de la que he venido hablando respecto del carácter del poeta-rey; por un lado, un hombre sensible, amante, cortesano, y por otro, un soberano autoritario e incluso cruel: "aunque era encantador / inspiraba terror claro" (De Jolly 73).

Más adelante, en el mismo poema, esta tensión entre terror y placer que, insisto, está muy presente a lo largo de todo el poemario, e incluso se constituye en uno de sus rasgos más fundamentales, se expresa de una manera notable:

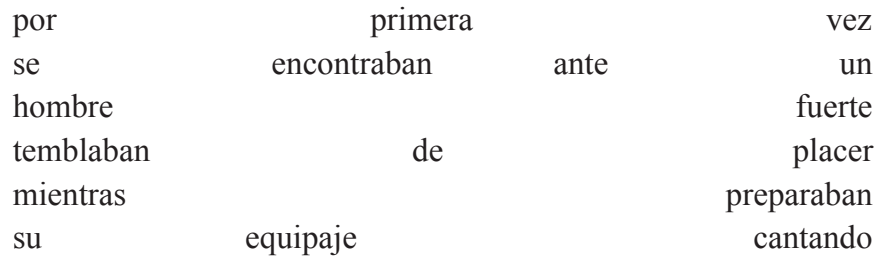

(De Jolly 73)

Esta contradicción entre el miedo que produce este "hombre con voluntad de hierro" y el efecto de placer entre los súbditos echados (¿exiliados?) del reino es muy sugerente. Del mismo modo que el canto (signo de alegría o celebración) acompaña los preparativos de la huida. Así como placer y terror van de la mano en este poema, tal vez no sea demasiado forzado ver ahí también un sutil eco con la también ambigua y compleja relación que se puede llegar a establecer entre un torturador y quien es torturado, o entre un secuestrador y su secuestrado (en la medida en que este último erotiza o vuelve afectivo el vínculo que el primero establece con él ${ }^{14}$ ).

Siguiendo con el desarrollo de esta voluntad soberana, hacia el final del libro ésta ha alcanzado su plenitud: "es nuevamente / el rey de Francia / el que se manifiesta / para afirmarlo / Versailles / mi radiante criatura" (De Jolly 97). Y, finalmente: "aquí está el coraje infinito / de luchar por la luz / indestructibles son las alegrías / de mi alma / aquí está / la afirmación de la vida / oh santa humanidad / Versailles debe quedar" (De Jolly 99).

14 Me refiero, con esto, al famoso "Síndrome de Estocolmo" que consiste, precisamente, en una reacción psicológica en la cual una persona secuestrada o retenida en contra de su voluntad desarrolla un vínculo afectivo y una relación de complicidad con su victimario. Con respecto a esto último, sería interesante vincular la obra de Paulo de Jolly con la de otro poeta chileno como Bruno Vidal, quien desarrolla una obra en la cual da lugar a la figura del torturador y la estetización del proceso de tortura. 
Entrando a poemas que escapan un poco de este aire celebratorio de los últimos poemas del libro, me interesa ver de qué manera a la vez que se le canta al monarca en su dimensión de hombre soberano, también se lo hace respecto de su lado más oscuro. Un poema como "Louis XIV y los pobres", por ejemplo, no deja de desconcertar por lo manifiesto y evidente de su maldad: "no repararé en injusticia alguna / con tal de obtener los pobres necesarios / los pobres merecen su destino" (De Jolly 74). Como decía al comienzo, con su inclusión dentro del libro se rompe de alguna manera la muy bien lograda ambigüedad enunciativa del hablante, que transita incluso dentro de un mismo poema entre la inocencia, el goce, la ironía y la crueldad. Esta perfección, sostenida en la incapacidad de apresar a este hablante siempre móvil e impreciso, se quiebra con un poema como este que, finalmente, lo que hace es hacer descender y fijar desde dónde es que se enuncia no solo éste, sino que, de alguna manera, todo el poemario. Si acordamos, junto al propio testimonio de Antonio Cussen, que el Louis XIV no es solo una recopilación de los poemas versallescos de Paulo de Jolly, sino que en su edición siempre estuvo presente la idea de que éste tuviera una pequeña narrativa como hilo conductor latente que se desarrollara a lo largo de todo el poemario, entonces efectivamente y a pesar de las aprehensiones del mismo Cussen, "Louis XIV y los pobres" permite y justifica una lectura de esta obra desde su lado más oscuro: el autoritarismo, la crueldad e incluso, como lo advertía Rivas, desde su "perturbadora belleza fascista" (35).

A este aspecto tanto del rey como del poemario está muy asociada la construcción de la imagen del gobernante en tanto hombre de guerra. Como veíamos, esta es una dimensión muy importante de la grandeza histórica del Rey Sol. Conocido es que durante su reinado aumentó el poder y la influencia de Francia en Europa, peleando en tres grandes guerras: la Guerra de Holanda, la Guerra de los Nueve Años y la Guerra de la Sucesión Española. Además, siempre se mostró muy preocupado de engrandecer su ejército, lo cual fue fundamental para llevar a cabo sus reclamaciones territoriales y defender sus territorios. Tanto el sentido de entrega y compromiso con el bienestar del Estado francés como la dimensión del monarca guerrero quedan muy bien expuestas en el siguiente poema:

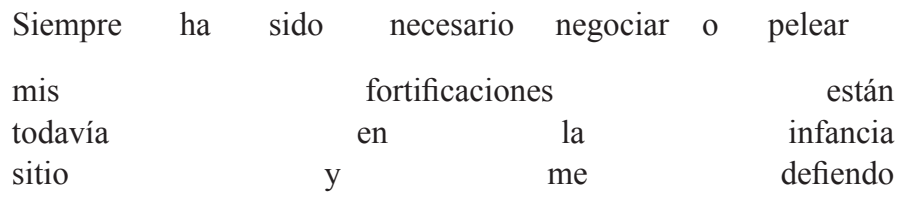




\begin{tabular}{|c|c|c|c|c|c|}
\hline con & dos & o & seis & & cañones \\
\hline uso & picas & $\mathrm{y}$ & arcabuces & & utilizo \\
\hline mucho & & la & & & espada \\
\hline la & guerra & & la & & declaro \\
\hline mediante & & un & & & heraldo \\
\hline por & ese & valor & que & & interés \\
\hline público & & $\mathrm{y}$ & la & & justicia \\
\hline me & piden & que & jamás & & sea \\
\hline $\mathrm{a}$ & $\mathrm{t}$ & $\mathrm{e}$ & $\mathrm{a}$ & d & o \\
\hline me & & & la & & coraza \\
\hline $\mathrm{y}$ & marcho & $\mathrm{a}$ & la & & guerra \\
\hline
\end{tabular}

(De Jolly 14)

Este poema, cuarto dentro del libro, da cuenta de lo que mencionaba respecto del proceso formativo del poeta-rey, proceso que se manifiesta también en la construcción del Palacio de Versalles (el signo visible tanto de este proceso como de la sacralización del soberano) y en el afianzamiento del poderío del monarca. Los primeros versos dicen: "mis fortificaciones están / todavía en la infancia" (De Jolly 14), es decir, al igual que él están en camino de convertirse en lo que serán. Como vemos a partir de este poema, se trata de un soberano totalmente entregado y comprometido con su labor de dirigir y cuidar el Estado. Eso sí, es llamativo que declara la guerra a sus enemigos para proteger la integridad de un valor al parecer tan primordial que no es necesario revelar cuál es: "la guerra la declaro / mediante un heraldo / por ese valor que el interés / público y la justicia / me piden que jamás sea / alterado" (De Jolly 14). A pesar de que no sepamos de qué valor está hablando, finalmente se trata de un monarca que es capaz de abandonar la comodidad de su palacio para investirse en su traje de guerrero: "me pongo la coraza / y marcho a la guerra" (De Jolly 14). Aquí la dimensión militarizada de quien gobierna inevitablemente resuena con la figura para quien este Rey Sol se levanta como modelo a seguir.

En otro poema dentro de esta misma línea, que lleva el título de la autoedición del 2003, "Príncipes, duques y mariscales de Francia", se lo describe como: "valiente y aficionado / a las armas" (De Jolly 32), para luego anunciar: 


$\begin{array}{lcrr}\text { dicen } & \text { que } & \text { de } & \text { niño } \\ \text { jugué } & \text { en } \quad \text { Versailles } & & \\ \text { porque } & \text { quería } & \\ \text { ser } & & \text { monarca }\end{array}$

(De Jolly 32)

Es interesante fijarse en cómo termina este poema, no solo porque se establece claramente la dimensión guerrera del monarca y de paso señala esta especie de predestinación del Rey Sol, sino porque también se evidencia aquella ruptura del poemario respecto de la verdadera historia. Imposible que Louis XIV haya jugado en Versalles cuando niño porque, como sabemos, este Palacio comienza a ser construido, en su primera etapa, en 1661, cuando éste ya tenía 23 años. Históricamente, el Palacio ha sido comprendido como la culminación de la política de protección de las artes que impulsó Louis XIV durante su reinado, política que consistió por sobre todo en la sacralización del soberano. Es importante precisar que se trata de la culminación de su política no solo porque ahí es donde desarrolló gran parte su gran proyecto de impulso de las artes, sino que también y sobre todo porque el edificio mismo es el signo visible de todo el esplendor y poderío tanto del rey como del Estado francés. Roger Chartier advierte que con la figura del rey Louis XIV se habría producido una unificación entre el cuerpo político y el cuerpo histórico del monarca, modificando, con esto, la idea misma de representación de un modo radical; el significado pasa a estar en el cuerpo, es decir, la imagen hace al rey (82). Tomando esto en cuenta, qué imagen más patente y efectiva que un palacio entero, con sus jardines y sus fuentes de agua.

Por otra parte, como es sabido, Moliére, Racine, Lully, Rigaud, entre muchos otros arquitectos, músicos y escultores, a la vez que fueron beneficiados con la protección y mecenazgo del rey, a cambio le debían muestras de veneración. De hecho, gran parte de sus obras fueron creadas -al menos en parte- con la finalidad de enaltecer la gloria del monarca. Señalo esto porque desde este conocido vínculo entre Louis XIV y los escritores y artistas que crearon bajo su reinado, desde una perspectiva más histórica bien se pudiera cuestionar la pertinencia de la utilización de la idea del "Barroco de Estado" para comprender la obra de Paulo de Jolly, en la medida en que aquella relación de dependencia y mecenazgo resulta ser un modelo mucho más cercano. Coincido plenamente en la proximidad y en la pertinencia, pero me parece que este modelo desconoce y sobre todo es incapaz de incorporar un aspecto que, como hemos visto, es también parte importante de esta obra: 
su lado perverso y más oscuro, asociado sobre todo a la idea de proponerlo como modelo de gobierno ideal para Pinochet. Frente a esto, la concepción del arte como enaltecimiento de la gloria del monarca se vuelve limitada, siendo bastante más pertinente esta comprensión del Barroco como "Barroco de Estado", entendido como el lenguaje oficial del imperio al servicio de una determinada estructura de dominación. Un discurso, en definitiva, que forma parte de un proyecto político y económico expansionista que pretendía unificar en torno a un rey, a un dios, y a un solo idioma, todo el dominio imperial.

En este sentido, el canto y la glorificación del monarca soberano y del monarca guerrero que ofrece Paulo de Jolly en su Louis XIV, al tiempo que recupera y legitima el absolutismo como forma ideal de gobierno, se ofrece también como un discurso puesto al servicio de una estructura de dominación, la estructura de la dictadura militar. Un régimen mucho más afín, en términos tonales, con un poema como "Louis XIV y los pobres", con este rey "valiente y aficionado a las armas", y sobre todo con los enigmáticos versos que cierran el poema "Louis XIV y la muerte":

la

había

el

$\mathrm{v}$

de

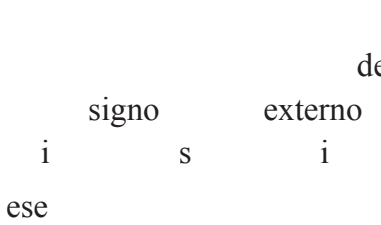

muerte

de

b $\quad 1 \quad$ y

predominio

(de Jolly 95)

Por muchos paseos por los jardines Palais-Royal, fiestas en la corte, emplumados marqueses y elegantes madames que compongan este pequeño universo, las resonancias de estos últimos versos no dejan de ser escalofriantes. De hecho, la perturbadora belleza de este conjunto de poemas queda manifiesta a partir de estos últimos versos que nos ponen en el incómodo lugar de preguntarnos cómo puede ser que un poemario que alaba al fascismo de Estado sea, al mismo tiempo, de una belleza fascinante. A partir de estas contraposiciones o ambigüedades irresueltas de abyección y belleza, o de terror y placer (a propósito del poema "Un hombre con voluntad de hierro") se hace evidente que Paulo de Jolly y su Luis XIV incomodan. Así, a pesar de que la lectura de ésta como una poesía cándida y excéntrica sea la más común, estas dimensiones más "oscuras" son una constante del Louis XIV. Efectivamente, como se atrevía a escribir Filebo en su breve reseña de 1985, "Louis XIV. La prospérité des armes de France”, el malentendido se encuentra en pensar 
que Paulo de Jolly está solo hablando de un siglo remoto al cual canoniza, como si ésta se tratara de una poesía histórica en el mismo sentido en que existe una novela histórica (Milán 23). Como hemos visto, en esta obra el cuidadoso trabajo con la historia y con su propio tiempo, en todo sentido, está muy presente, y es precisamente a partir de este minucioso y obsesivo cometido que Paulo de Jolly logra deslizar "su mirada profunda sobre un mundo que le es completamente actual" (Filebo 8). Como he pretendido mostrar, con toda su profundidad, con toda su delicadeza, esta mirada sobre su propio tiempo vinculada a su deseo de recuperación y legitimación del absolutismo como modelo ideal de gobierno, puesto en el contexto que le corresponde, está lejos de ser "una evasión en el tiempo de un espacio inhóspito" (Lihn 31). No hay distancia ni escapismo más mentiroso que ese. Louis XIV es un libro escrito en Chile a fines de los setenta y principios de los ochenta y, si bien nos podemos distraer por el resplandor de esta "ciudad de los candelabros de plata", si se mira con atención, las marcas de su propio tiempo saltan a la vista.

\section{BIBLIOGRAFÍA}

Beverley, John. Del Lazarillo al sandinismo: estudios sobre la función ideológica de la literatura española e hispanoamericana. Mineappolis: The Prisma Insitute, 1987.

Brito, Eugenia. Filiaciones. Santiago: Van, 1986.

Chartier, Roger. Espacio público, crítica y desacralización en el siglo XVIII. Los orígenes culturales de la revolución francesa. Barcelona: Gedisa, 2002.

Cussen, Felipe. "Poesía de Lujo". Revista Universitaria n 94, 2006.

De Jolly, Paulo. "Mítico poeta chileno perdido aparece después de dos décadas". Entr. Jazmín Lolas. Las Últimas Noticias, marzo, 2004.

"Paulo de Jolly, poeta: «En Chile se puede vivir como rico sin serlo»”. Entr. Ana María Sanhueza. The Clinic n ${ }^{\circ}$ 192, nov. 2006: 13.

Louis XIV. Puerto Rico: Edición Premio Mairena de poesía, 1982.

Louis XIV. Santiago: Ediciones Tajamar, 2006.

Príncipes, Duques y Mariscales de Francia. Santiago de Chile: autoedición, 2003.

Una belleza nueva. Conversando con Cristián Warnken. Entr. Cristián Warnken. TVN, octubre, 2006. Web. 12 ene 2012. 8 febrero 2012. http://www.unabellezanueva.org/ pablo-de-jolly/

Fariña, Soledad. La vocal de la tierra. Santiago: Cuarto Propio, 1999.

Filebo. "Dieciochesco, pero muy siglo XX”. Las Últimas Noticias. 1 abr. 1984: El Rincón de los libros. 

jun. 1985.

"Paulo de Jolly: «La prosperité des armes de France". Las Últimas Noticias. 5

Lihn, Enrique. "Louis XIV soy yo”. Cauce. 3-9 sept. 1985: 31.

Milán, Eduardo. "Prólogo". Pulir huesos. Veintitrés poetas latinoamericanos (1950-1965). Madrid: Galaxia Gutemberg, 2007.

Millán, Gonzalo. La Ciudad. Santiago: Cuarto Propio, 1994.

Moraña, Mabel. Viaje al silencio. Exploraciones del discurso barroco. México: Universidad Autónoma de México, 1998.

Rivas, Matías. "El rey facho". The Clinic. 9 nov. 2006: 35.

Voltaire. El siglo de Luis XIV. México: Fondo de Cultura Económica, 1954. 